\title{
STUDY OF ATOMIC SYSTEMS IN STRONG LASER FIELDS: SPECTRAL HIERARCHY, DYNAMICAL STABILIZATION AND GENERATION OF ULTRA-SHORT VUV AND X-RAY PULSES
}

\author{
A. V. Glushkov", I. M. Shpinareva, V. M. Ignatenko and V. I. Gura \\ Odessa National Polytechnical University, Odessa, Ukraine
}

\begin{abstract}
Summary
STUDY OF ATOMIC SYSTEMS IN STRONG LASER FIELDS: SPECTRAL HIERARCHY, DYNAMICAL STABILIZATION AND GENERATION OF ULTRA-SHORT VUV AND X-RAY PULSES
\end{abstract}

\section{A. V. Glushkov, I. M. Shpinareva, V. M. Ignatenko and V. I. Gura}

A new method for sensing a spectral hierarchy and dynamical stabilisation in atomic systems in the intense laser field is presented.It is carried out modeling generation of the atto-second VUV and X-ray pulses under ionization of atomic systems by femto-second optical pulse. The theory of studied phenomena is the physical basis for construction of the new nano-atomic elements and devices, including sensors, sources of VUV and X-ray radiation, quantum Carnot engine, single-atomic lasers, quantum computers elements etc.

Key words: sensing, atomic system, laser field, spectral hierarchy, stabilisation, attosecond VUV and X-ray pulses

\section{Анотація \\ ВИВЧЕННЯ АТОМНИХ СИСТЕМ У ІНТЕНСИВНОМУ ПОЛІ ЛАЗЕРНОГО ВИПРОМІНЮВАННЯ: СПЕКТРАЛЬНА ІЕРАРХІЯ, ДИНАМІЧНА СТАБІЛІЗАЦІЯ ТА ГЕНЕРАЦІЯ УЛЬТРАКОРОТКИХ ІМПУЛЬСІВ ВУФ ТА РЕНТГЕНІВСЬКОГО ДІАПАЗОНІВ}

О. В. Глуиков, І. М. Шпінарева, В. М. Ігнатенко, В. І. Гура

\begin{abstract}
Розвинуто новий метод детектування ефектів спектральної ієрархії і динамічної стабілізації в атомних системах у сильному полі лазерного випромінювання. Виконано моделювання генерації аттосекундних імпульсів ВУФ а рентгенівського діапазону при іонізації втомних систем фемтосекундним оптичним імпульсом. Теорія шуканих явищ може служити фізичною основою для побудування нових нано-атомних елементів, приладів та технологій (сенсори, джерела ВУФ та рентгенівського випромінювання, квантові машини Карно, одноатомні лазери, елементи квантових комп’ютерів тощо).
\end{abstract}

Ключові слова: детектування, атомна система, поле лазерного випромінювання, спектральна ієрархія, стабілізація, аттосекундні ВУФ та рентгенівські імпульси 


\title{
Аннотация
ИЗУЧЕНИЕ АТОМНЫХ СИСТЕМ В ИНТЕНСИВНОМ ПОЛЕ ЛАЗЕРНОГО ИЗЛУЧЕНИЯ: СПЕКТРАЛЬНАЯ ИЕРАРХИЯ, ДИНАМИЧЕСКАЯ СТАБИЛИЗАЦИЯ И ГЕНЕРАЦИИ УЛЬТРАКОРОТКИХ ИМПУЛЬСОВ ВУФ И РЕНТГЕНОВСКОГО ДАИПАЗОНОВ

\author{
А. В. Глуиков, И. М. Шиинарева, В. М. Игнатенко, В. И. Гура
}

Развит новый метод детектирования эффектов спектральной иерархии и динамической стабилизации в атомных системах в сильном поле лазерного излучения. Теория искомых явлений может служить физической основой для создания новых нано-атомных элементов и приборов (сенсоры, источники ВУФ и рентгеновского излучения, квантовые машины Карно, одноатомные лазеры, элементы квантовых компьютеров и т.д.).

Ключевые слова: детектирование, атомная система, поле лазерного излучения, спектральная иерархия, стабилизация, аттосекундные ВУФ и рентгеновские импульсы

\section{Introduction}

In last years the phenomena of dynamical chaos and dynamical stabilization attract a great interest as a manifestation of this effect in photo-optical systems may in a significant degree change a functional regime (e.g.[1-7]). Cited effect is usually observed in the physical systems and related to a type of nonlinear effects. As a rule, dynamical chaos is manifested in the quantum systems, which are not linear in a classic limit. Above especially effective manifestations of this effect in the quantum systems one could mention systems which interact with external, time dependent, for example laser, field. It has been discovered that dynamics of atomic and molecular, cluster and nano-optical systems in a laser field has features of the random, stochastic kind and its realization does not require the specific conditions. The importance of studying a phenomenon of stochasticity or quantum chaos in dynamical systems in laser field is provided by a whole number of technical applications, including a necessity of understanding chaotic features in a work of different electronic devices and systems. The important topic of the laseratomic dynamics and hierarchy systems physics is connected with governing and control of quantum chaotic diffusion and stabilisation effects in atomic systems in the intense laser field (especially important case is atoms in electromagnetic traps and heat bath) [1-20]. The principal aim of coherent control is to steer a quantum system towards a desired final state through interaction with light while simultaneously inhibiting paths leading to undesirable outcomes. Controlling mechanisms have been proposed and demonstrated for atomic and solid-state systems. Gibson performs calculations for three-level systems and 1D model of a two-electron molecule (e.g.[2-5]. Transitions to excited state occur via a 12photon interaction for an $800 \mathrm{~nm}$ intense pulse of length $244 \mathrm{au}$, or just over 2 cycles. The stabilization dynamics of model He beyond the dipole approximation and with two active electrons was is investigated [6] in the presence of a high-intensity and high-frequency laser pulse. We show that the magnetic-field component of the laser pulse and the electron-electron interaction jointly suppress the dichotomy of the wavefunctions as well as the atomic stabilization. There may exist a laser frequency and intensity regime in which the total ionization yield decreases with increasing laser amplitude. In the near future, free electron lasers will further deliver laser pulses of such high frequencies and intensities to meet the conditions needed for the stabilization of atomic systems more easily. Along with those technological developments, a wide range of theoretical methods including analytical model calculations, Monte Carlo simulations and numerical calculations have been applied to the ionization of hydrogen-like atoms. Further progress was achieved concerning the ionization and stabilization of atoms with two active electrons. In this paper an effective approach to adequate treating and sensing a spectral hierarchy and dynamical stabilisation in atomic systems in the intense laser field is considered and based on nonrelativistic and relativistic time-dependent complex rotation method (for atomic systems) and non-Hermitian Floquet formalism (for molecular systems). It is carried out modeling generation of the atto-second VUV and X-ray pulses under ionization of atomic systems by femto-second optical pulse. Presented theory of studied phenomena is the physical basis for construction of the new nano-atomic elements, sensors and devices. 


\section{Time dependent complex rotation method and non-Hermitian Floquet formalism}

The main idea of the complex rotation coordinates method which is earlier successfully used in solution of the quasi stationary states in static filed problems (e.g. $[12,14,15])$ is connected with transformation of coordinates: $r^{\prime}=\alpha r \exp (i \varphi)$ in Hamilton operator of a system. Their eigen-values are corresponding to the quasi stationary states, remain unchanged; the eigen functions are transited to a space of quadratically integrated functions. As result, a problem of defining energies is led to a search of eigen-values of non-hermit matrice. Let us consider two-electron atom. in an external elec-tromagnetic field: $F(t)=F_{o}(t) \cos (\omega t) \quad\left(F_{o}\right.$ is amplitude; for circularly polarized wave $F(t)=F_{o}\{\cos \omega t, \sin \omega t, 0\}$. Within the quasi stationary states problem solution, the equation on quasi stationary states for atom in a field of circularly polarized wave in the system, rotating with the field frequency, is as follows: (the atomic units are used: $\mathrm{e}=\mathrm{h}=\mathrm{m}=1 ; 1$ a.u.energy $=27,212 \mathrm{eV}$; 1 a.u.length $=0,529 \AA$ etc.):

$$
\begin{gathered}
\left(-1 / 2 \cdot \nabla^{2}-r^{-1}+V_{c}(r)+\omega L_{z}+\right. \\
\left.+F_{o} x\right) \Psi_{E}(r)=E \Psi_{E}(r)
\end{gathered}
$$

Here $\omega$ is the field frequaency; $L_{z}$ is z-th component of the full pulse moment; $V_{c}(r)$ is the model potential, which describes an interaction of electron with field of others. After the complex coordinates transformation the Eq. (1) is rewritten as follows:

$$
\begin{gathered}
\left(-1 / 2 \cdot \nabla^{2} e^{-2 i \varphi}-r^{-1} e^{-i \varphi}+V_{c}(r) e^{-i \varphi}+\omega L_{z}+\right. \\
\left.+F_{o} x e^{i \varphi}\right) \Psi_{E}\left(r e^{i \varphi}\right)=\left(E-E_{n}^{o}\right) \Psi_{E}\left(r e^{i \varphi}\right)
\end{gathered}
$$

Here $E_{n}^{o}=-1 / 2(n-\delta)^{2}$ is the non-perturbed energy value; $\delta$ is a quantum defect. The quadratic integrality of the quasi-stationary state functions is provided under values of the angle for complex rotation of coordinates $\varphi$, and cited values are determined by the following inequalities:

$$
\begin{gathered}
\mid \arg [-(E+N \omega)]^{1 / 2}<\varphi< \\
<\pi / 2-\arg \{-[E+(N-1) \omega]\}^{1 / 2}
\end{gathered}
$$

Here $N$ - is the threshold number of photons needed for ionization. Under choice of the finite basis for diagonalization of (2) the complex eigen-values are dependent upon the angle $\varphi$ as a parameter. Standard approach is in a choice of the definitive exactness of calculation and in further the basis size is chosen in such a way that their variations do not change the exactness of calculation. In our opinion, the most ef- fective procedure is an use of the optimal basis of the operator perturbation theory in the Stark problem for the non hydrogen atom [17] with application the well known Hellman potential as the potential $V_{c}(r)$. In further a problem is resulted in stationary task on the eigen-values and eigen-vectors for the matrice $\boldsymbol{A}$ :

$$
\begin{gathered}
\boldsymbol{A} \boldsymbol{b}=\left(E_{n}^{o}-E_{n}\right) \boldsymbol{b} \\
A_{n l m, n_{1} l m_{1}=\delta_{l, l_{1}} \delta_{m, m_{1}}}\left\{<n l m \mid n_{1 l_{1} m_{1}}>\times\right. \\
\times\left[\left(n_{1}+l_{1}+1\right) / v \cdot \exp (-2 i \varphi)-\exp (-i \varphi)\right]+ \\
\left.\delta_{n, n_{1}}\left(E_{n}^{o}-1 / 2 v^{2}+\omega m\right)\right\}+ \\
+F_{o} \exp (-i \varphi)<n l m|x| n_{1 l_{1} m_{1}}>
\end{gathered}
$$

Here $\mid n l m>$ is a radial part of the basis functions. A full diagonalization of the matrice (4) is quite complicated task. As usually, it is possible to make a search for one eigen-value, which is transited to the state $E_{n}^{o}$ under switching on a field. A solution of determining the maximal eigen-value and the corresponding eigen-vector is realized by usual iterative methods (cm.[12,15,21]). Relativistic version of this method operates with the Dirack hamiltonian for atomic system. Under the complex transformation of the spatial variables: $: r^{\prime}=\alpha r \exp (i \varphi)$ the Dirac hamiltonian is as follows:

$$
\begin{aligned}
H(\varphi)= & {\left[\alpha p-\alpha Z / r+V_{c}(r)\right] \exp (-i \varphi)+} \\
& +\beta-(\alpha)^{1 / 2} F z \exp (-i \varphi)
\end{aligned}
$$

where $\alpha$ is the fine structure constant, $V_{c}$ is the screening potential, other symbols are standard. To diagonalize the complex rotated Hamiltonian (5), one should chose a proper basis. Alternative versions are presented in refs.[12,14]. In the time dependent formalism, one should solve the corresponding time dependent Dirak (SchrÖdinger) equation of the following type:

$$
i \frac{\partial \Psi}{\partial t}=\left[H_{o}\left(e^{i \varphi} r\right)+F \sin \omega t e^{i \varphi} z\right] \Psi
$$

The wave function of atomic (or molecular system) in the external field is represented as expansion on the basis of the corresponding wave functions for stationary states $(F=0)$. Substitution of such expansion to the master equation (6) allows to get the system of diffrential equations, which can be solved by the Runge-Cutt method .

Using considered methods for molecular systems, in particular, diatomics, requires the solution of two centre problem of quantum mechanics at the 
first step. Because of the axe symmetry of task, it is natural to use the prolate spheroidal co-ordinates. Stationary problem is reduced to solving the master differential equations system, which has the following form (e.g.[21,22]):

$$
\begin{gathered}
\left\{d / d \mu\left(\mu^{2}-1\right) d / d \mu-\left[\lambda_{m l}+m^{2} /\left(\mu^{2}-1\right)+\right.\right. \\
\left.+\mu^{2} c^{2}+R_{a b} g(\mu) / 2\right\} T_{n l m}=0 \\
\left\{d / d \eta\left(-\eta^{2}+1\right) d / d \eta+\right. \\
\left.+\left[\lambda_{m l}+\eta^{2} c^{2} m^{2}\left(1-\eta^{2}\right)\right]\right\} S_{l m}=0,\left\{d^{2} / d \varphi^{2}+m^{2}\right\} \Sigma_{m}=0
\end{gathered}
$$

where the model ion-electron potential $\Phi(\mu, \eta)=$ $\left.-2 a \exp \left[-\alpha R_{a b} \mu\right]\right] /\left[R_{a b}\left(\mu^{2}-\eta^{2}\right)\right]=g(\mu) /\left(\mu^{2}-\eta^{2}\right)$ for multielectron diatomics and $\exp [\ldots]=1$ for the ion of $\mathrm{H}_{2}^{+}[23,24]$. Wave function can be represented as follows: $\Psi_{n l m}=T_{n l m}(\mu) S_{l m}(\eta) \Sigma_{m}(\varphi)$. One- electron energy $E=-2 c^{2} / R a b^{2}$ is dependent upon the ground quantum number and also the symmetry of quantum numbers $l, m ; \lambda_{m l}$ is a coupling constant. Usual molecular orbitals (MO) correspond to the orbitals-solutions (MOS) of (11) as follows: (MO)$(M O S)=1 \sigma_{g}-1 s \sigma ; 1 \sigma_{u}-2 p \sigma ; 2 \sigma_{g}-2 s \sigma ; 2 \sigma_{u}-3 p \sigma ; 3 \sigma_{g}$ $-3 d \sigma ; 1 \pi_{u}-2 p \pi ; 1 \pi_{g}-3 d \pi ; 3 \sigma_{u}-4 p \sigma$. A new, more effective method of the eigen-values definition and functions problem solution, which is based on the operator perturbation theory and Runge-Cutt integration procedure, was proposed in $[21,22]$. This basis is further used in the time-dependent problem. Next action includes the following steps: i). generalized complex scaling pseudospectral discretization of wave function and hamiltonian in the prolate spheroidal coordinates (methodics [13]); ii). construction and diagonalization of time evolution operator for one optical cycle, which yields the complex quasienergy eigenvalues and Floquet eigenstates (e.g.[13]); iii). time propagation of the selected Floquet states and evaluation of the time-dependent expectation values of dipole moment, momentum with further Fourier analysis of the above cited quantities to produce the harmonic generation rates [25].

\section{Results and discussion}

Let us start from comsidering stabilization of helium (study of the 2D two-electron atom) in intense high-frequency laser pulses. For the numerical integrations, we have chosen grids with equidistant spacing of $0.2 \mathrm{au}$ and total sizes ranging between 409.6 and 512.0 au in each spatial dimension; these parameters have been chosen to ensure that the wavepackets can evolve without boundary problems in position space while their maximal momenta are resolved. In figure 1 the ionization probability of the outer electron in dependence of the peak laser electric-field amplitude is depicted, where laser pulses of four optical cycles linear turn-on and four cycles constant intensity of frequency $\omega=1$ a.u. have been employed. The results from ref.[6] are denoted by squares and three-angles. Our results are denoted by solid lines. Using more correct numerical procedure in comparison with [6] provides more accuracy of our data. One can observe in figure 1 the typical features of stabilization: after a rise in ionization probability with increasing laser peak intensity, ionization is suppressed for a certain intensity regime; after this region of stabilization, the ionization probability rises again with increasing intensity, as expected due to the Lorentz force. At high laser intensities with electron-electron repulsion, the probability for ionization is higher for the outer electron, while at a laser electric field around $\mathrm{E}_{\mathrm{o}}=5,3 \mathrm{au}$ a substantially larger fraction of the inner electron wavefunction ionizes. The largest degree of stabilization is not at the same intensity for both electrons; theouter electron stabilizes best at $\mathrm{E}_{\mathrm{o}}=8 \mathrm{au}$, the inner at $\mathrm{E}_{\mathrm{o}}=10$ au maximal electric-field strength. The general behaviour was explained in ref. [6] and connected with the stronger interaction between the inner electron and nucleus. Regarding the role of ionic core, tight binding to the nucleus disturbs the regular motion of the electrons in the laser field. Thus higher laser intensities are necessary for optimal stabilization for the inner electron compared to outer one.

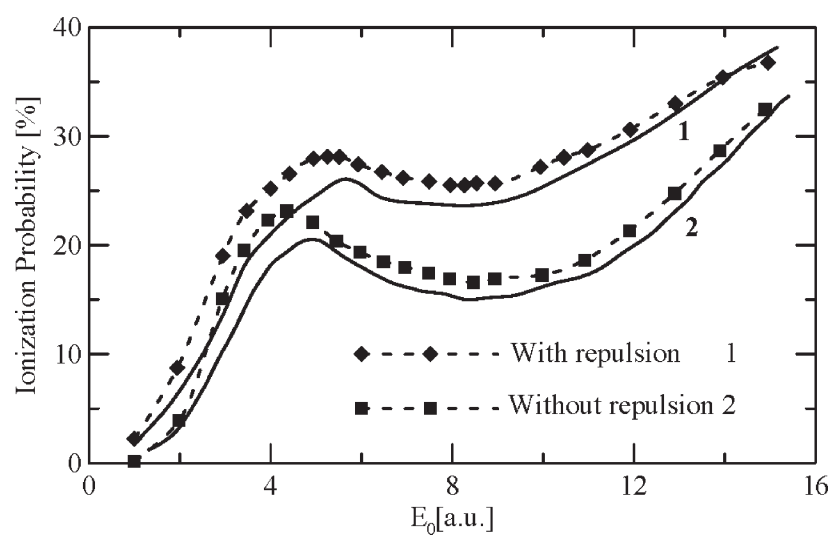

Figure 1. Ionization probability of the outer electron as a function of the maximal electric-field strength $E_{0}$ $(\omega=1 \mathrm{au})$, depending on whether the electron-electron repulsion has been taken into account or neglected.(data from ref.[6] are denoted by squares and triangles; our data-by solid lines).

Furthermore, stabilization breaks down at higher intensities for the inner electron due to the stronger 
binding by the nucleus. Presence of electron repulsion is crucial because it effectively enhances the binding of the inner electron and weakens it due to shielding for the outer electron. The relative ionization rates are virtually the same for both electrons, showing max for ionization at $\mathrm{E}_{\mathrm{o}}=4,4$ au and min at $\sim \mathrm{E}_{\mathrm{o}}=8$,5au peak electric field strength. The overall ionization probability here is lower than when the interaction between the electrons is taken into account, which is most pronounced in the intensity regime where stabilization emerges (see figure). So, the repulsion between electrons in a 2D two-electron atom reduces stabilization jointly with the magnetically induced Lorentz force. In result the data from [6] indicate on increasing effect in the overall ionization probability. From this point of view, our results look more physically reasonable.

In figure 2 we present calculated multi-photon ionization rates of $\mathrm{H}_{2}^{+}$in the upper (a) and lower (b) Floquet states vs the internuclear distance $R$. The wavelength of the laser field is $532 \mathrm{~nm}$ and the laser intensity is $5 \cdot 10^{13} \mathrm{~W} / \mathrm{cm}^{2}$.
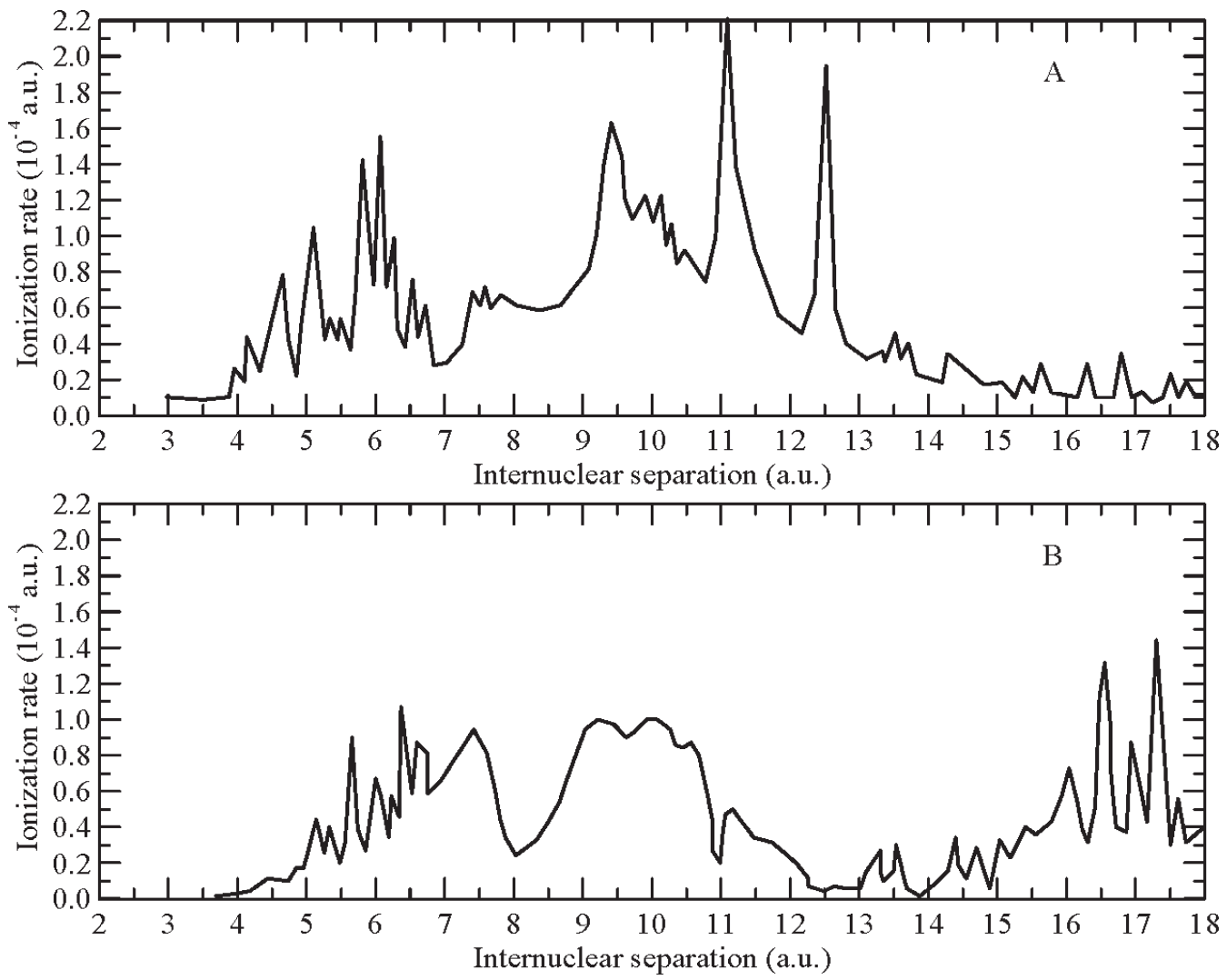

Figure 2. Multi-photon ionization rates of $\mathrm{H}_{2}^{+}$in the upper (A) and lower (B) Floquet states vs $R$.

In qualitative relation the obtained data are corresponding to results of the sophisticated calculation by Telnov-Chu [13]. When going from smaller to higher internuclear distances and approaching the correspnding threshold, a series of resonances with the excited states of $\mathrm{H}_{2}^{+}$is encountered which causes a significant enhancement in the ionization process. A resonances series is clearly seen atound 6,5 a.u. Another large resonance series is spread from 10 to 18a.u. Analogous resonances in the ionization rate as a function of $R$ were revealed in the previous Floquet calculaiton by Madsen, Plummer, McCann (e.g.[13]) at shorter wavelengths 212 and $248 \mathrm{~nm}$.
Further we present the results of our modelling the generation of the atto-second VUV and X-ray pulses under ionization of molecular system $2 \mathrm{D} \mathrm{H}_{2}^{+}$ by femto-second optical pulse. Figure 3 presentes the spectra of molecular response for different internuclear distances 2.5, 3.5, 7.4, 16a.u. with smoothed Coulomb potential. These data are qualitatively similar to the results [20].

Our calculation confirms the conclusion that the generation of the atto-second pulses (the splashes in fig.3) in molecular system is more profitable (as minimum the 1-2 orders) than in similar atomic one. Corresponding spectral dependence of atomic (atom of $\mathrm{H}$ ) 
response is also presented in fig.3. It is important to note that the corresponding response at the internuclear distance 7.4 overcomes the response for molecule in the equilibrium state. Last experimental achievements in field of generating high harmonics of optical radia- tion during atomic ionization by powerful femtosecond laser pulses demonstrated a possibility of construction of the compact sources of VUV radiation (e.g.[2,20]). The effects considered in this paper give hope of the further progress in this direction.

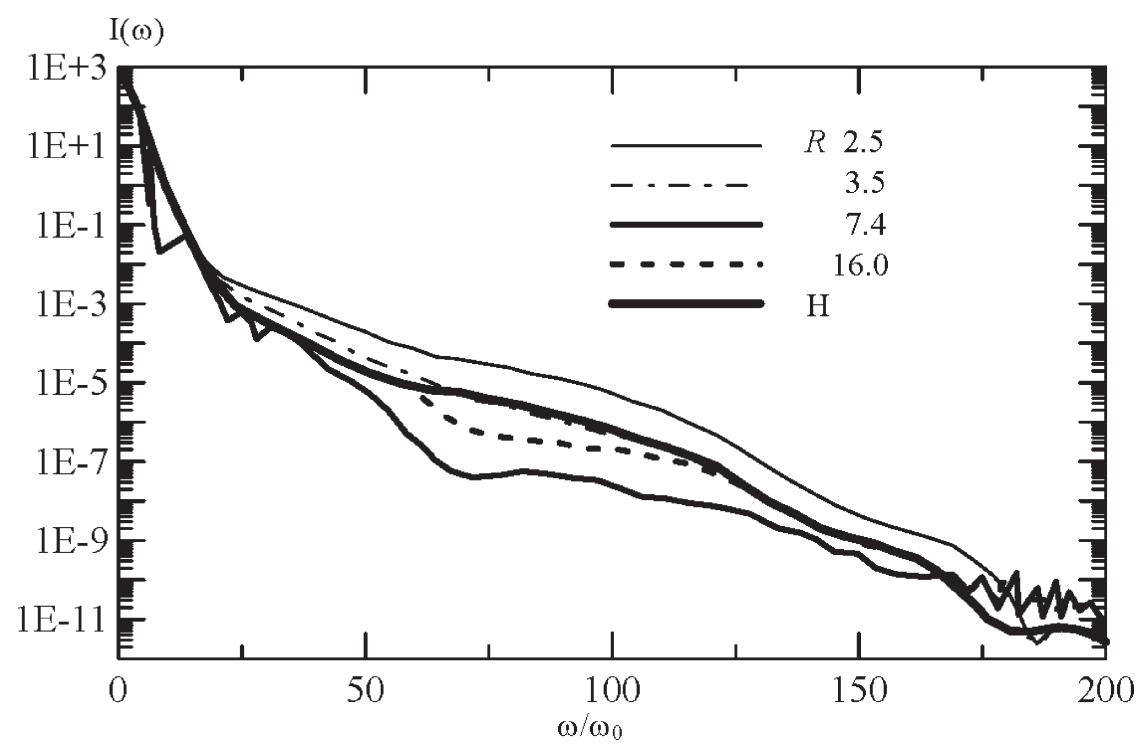

Fig.3. Molecular response (spectral dependence) under ionization of $\mathrm{H}_{2}^{+}$ by femto-second optical pulse ( $\omega_{0}$ - the laser field frequency) .

In conclusion let us note that the presented theory of studied phenomena can be used as the physical basis for the construction of new nano-atomic devices (sensors, sources of VUV and X-ray radiation, quantum Carnot engine, single-atomic lasers, quantum computers elements etc).

Acknowledgement. Authors would like to thank Professors W.Kohn, I.Kaplan, C.Maruani, A Becker, M Bonitz, A.Theophilou, Ya.Lepikh for useful discussions. The valuable comments of anonymous referees are appreciated. One of the authors (A.Glushkov) acknowledges the support of the Christian-Albrechts-University of Kiel.

\section{References}

1. Delone N.B., Krynov V.P. Stabilisation of atom in a field of laser radiation// Usp. Phys. Nauk. 1995. - Vol.165, N11. - P.1295-1321.

2. Delone N.B., Krynov V.P., Tunnel and above threshold ionization of atoms and ions in a field of laser radiation// Usp. Phys. Nauk. - 1998. Vol.168, N5. - P.531-549.

3. Fedorov M.V., Stabilisation of atom in a strong field of laser radiation// Usp. Phys. Nauk. - 1999. - Vol.169, N1. - P.66-71.

4. Plummer M., Noble C.J., Non-hermitiam dynam- ics of argon atoms at $248 \mathrm{~nm} / /$ J.Phys. B: At. Mol. Opt. Phys. - 2003. - Vol.36. - P.L219-L226.

5. Glushkov A.V., Prepelitsa G.P., Svinarenko A.A. Sensing the stochastic laser pulse structure and chaotic and photon-correlation effects in the non-linear multi-photon atomic dynamics in laser and dc electric field// Sensors Electr. \& Microsyst.Techn. - 2004. - N2. - P.16-22.

6. Staudt A., Keitel C.H., Stabilization of helium in intense high-frequaency laser pulses beyond the dipole approximation// J.Phys. B: At. Mol. Opt. Phys. — 2003. - Vol.36. - P.L203-L209.

7. Mercouris T., Nikolaides C.A. Solution of the many-electron many-photon problem for strong fields: Application to $\mathrm{Li}^{-}$in one and two-colour laser fields//Phys.Rev.A. — 2003. - Vol.67. P.063403-1-063403-12

8. Cheng T., Liu J., Chen S., Guo H. Rydber atoms in parallel microwave and magnetic fields- classical dynamics// Phys.Lett.A. — 2000. - V.265. — P. 384-390.

9. Hegerfeldt G.C., Henneberg R., Level statistics for continuum energy spectra with application to hydrogen atom in crossed electric \&magnetic fields// Phys.Rev.A. - 1994. - vol.49. - P.3531-3548 .

10. F.Benvenuto, G.Casati, D.L.Shepelyansky, Rydberg Stabilization of atoms in strong fields: "magic"mountain in chaotic sea// Z.Phys.B. 1996. - Vol. 94. - P.481-486. 
11. Glushkov A.V., Ivanov L.N., Radiation decay of atomic states: atomic residue and gauge non-invariant contributions// Phys.Lett.A. - 1992. Vol.170. - P.33-38.

12. Ivanov I.A., Ho Y.K., Complex rotation method for Dirac Hamiltonian//Phys.Rev A. - 2004. Vol.69. - P.023407(1-6).

13. Telnov D.A., Chu Shih-I., Ab initio study of highorder harmonic generation of $\mathrm{H}_{2}^{+}$in intense laser field: time-dependent non-Hermitian Floquet// Phys.Rev A. — 2005. — Vol.71. — P.013408(1-10).

14. A.V.Glushkov, A.P.Fedchuk, V.M.Ignatenko, Dynamical chaos in highly excited states of Rydberg atoms in an external electromagnetic field// Photoelectronics. - 2002. - N11. - P.18-20.

15. Glushkov A.V.,Malinovskaya S.V., Chernyakova Yu.G., Svinarenko A.A. Cooperative Laser-Electron-Nuclear Processes: QED Calculation of Electron Satellites Spectra for Multi-Charged Ion in Laser Field// Int.Journ.Quant.Chem. — 2004. Vol.99,N5. - P.889-898.

16. Glushkov A.V., Ivanov L.N., DC Strong Field Stark Effect: Consistent Quantum Mechanical Approach // J.Phys.B. At.Mol.Opt.Phys. — 1993. Vol.24. - P.L379-388.

17. Glushkov A.V., Ambrosov S., Ignatenko V., Korchevsky D., DC Strong Field Stark Effect for Non-hydrogenic Atoms: Consistent Quantum Mechanical Approach // Int.Journ.Quant.Chem. 2004. - Vol.99,N5. - P.936-940.

18. Glushkov A.V., Gurnitskaya E.P., et al, Consistent QED approach to calculation of electron-collision excitation cross-sections and strengths: Ne-like ions // Int. Journ.Quant.Chem. - 2005. Vol.104, N4 . - P. 562-569.

19. Glushkov A.V., Malinovskaya S.V., et al, Diagnostics of the collisionally pumped plasma and search of the optimal plasma parameters of x-ray lasing// J.Phys.CS. — 2005. — Vol.11. - P.188198.

20. Emelin M.Yu., Ryabikin M.Yu., Sergeev A.M. et al, On generation of atto-second pulses and high harmonics of radiation under ionization of molecules by ultra-short laser pulse// JETP Lett. 2003. — Vol.77. - P.254-259.

21. Glushkov A.V., Perturbation theory with model zeroth approximation for molecules// Sov. Journ. Phys.Chem. — 1991. — Vol.65. — P.2970-2976.

22. Glushkov A.V., New method of calculating spectra, bond energy, ionization potentials for negative molecular ions// Optics and Spectr. — 1992. Vol.72. - P.55-61.

23. Glushkov A.V., Effective quasi-particle valence hamiltonian of molecules in the comprehensive semi-empirical theory // Sov. Journ. Struct. Chem. - 1988. - Vol.29, N4. - C.3-10.

24. Glushkov A.V., New non-empirical approach to construction of effective potential of the valence electrons // Sov. Journ. Struct. Chem. - 1989. Vol.30, N1. - C.3-8.

25. Glushkov A.V., Relativistic multi-configuration time-dependent theory of self-consistent field for molecules//Sov.Phys.(Izv.Vuzov.Ser.Phys.). 1991-Vol.41. - N10. - P.29-38.

26. Glushkov A.V. Negative Ions of Inert Gases// JETP Lett. — 1992. — Vol.55, N2- C.95-98. 